\title{
PENGEMBANGAN SYIAR ISLAM DI KERAJAAN BONE PADA MASA PEMERINTAHAN LA MADDAREMMENG TAHUN (1625-1644 M)
}

\author{
Muhammad Kadril \\ Universitas Islam Negeri Alauddin Makassar \\ Email : muhammadkadril7@gmail.com
}

\begin{abstract}
The aimed of this research to know how far the role of $\mathrm{La}$ Maddaremmeng Sultan Muhammad Shaleh in doing Islam development magnigicience in Bone kingdom in the $17^{\text {th }}$ century, as far that became problems in this research, the researcher divided into several parts, they were: The effort La Maddaremmeng Sultan Muhammad Shaleh in Islam religion development magnigicience in Bone Kingdom, and the defiance was faced by La Maddaremmeng Sultan Muhammad Shaleh in applying the Islam values in Bone Kingdom. The kind of this research was history research.To reveal the reality of history that had been done in the $17^{\text {th }}$ century, so that the researcher used some approaches that were very relevant with this research. As far some approaches were used by the researcher were history approach, religion, and sociology.The result of this research, the researcher got some efforts that were done by La Maddaremmeng, which were slave abolition, made parewa syara', and did the purification of religion.
\end{abstract}

Keywords: Islam Magnigicience, Bone Kingdom, La Maddaremmeng.

\begin{abstract}
Abstrak
Tujuan penelitian ini untuk mengkaji sejauh mana peranan La Maddaremmeng Sultan Muhammad Shaleh dalam melakukan pengembangan syiar Islam di Kerajaan Bone pada abad XVII, adapun yang menjadi permasalahan dalam tulisan ini, penulis membagi ke dalam beberapa bagian diantaranya:Usaha La Maddaremmeng Sultan Muhammad Shaleh dalam Pengembangan syiar Agama Islam di Kerajaan Bone, dan tantangan yang dihadapi La Maddaremmeng Sultan Muhammad Shaleh dalam mengaplikasikan nilai-nilai Islam pada Kerajaan Bone. Jenis penelitian ini adalah penelitian sejarah. Untuk mengungkap realitas sejarah yang terjadi pada abad ke XVII, maka penulis mengunakan beberapa pendekatan yang tentu sangat relevan dengan penelitian ini. Adapun beberapa pendekatan yang digunakan oleh penulis yakni pendekatan sejarah, agama, dan sosiologi. Hasil penelitian ini, penulis mendapatkan beberapa usaha yang dilakukukan oleh $\mathrm{La}$ Maddaremmeng diantaranya penghapusan budak, membentuk parewa syara', dan melakukan pemurnian agama.
\end{abstract}

Kata Kunci : Syiar Islam, Kerajaan Bone dan La Maddaremmeng. 


\section{A. Pendahuluan}

Proses Islamisasi di Indonesia, terjadi pada abad XIII sebagai bukti adanya Kerajaan-Kerajaan Islam yang berdiri pada masa itu, salah satunya berada di Daerah Aceh yaitu Kerajaan Perlak (abad XIII) dan Kerajaan Islam Pasai (abad XIII) keduakerajaan ini adalah pintu masuknya Islam di kerajaan-kerajaan yang berada di Nusantara.Sebabkedua kerajaan ini, Islam tersebar di Pulau Jawa abad XV, Pulau Maluku abad XV, Pulau Sulawesi abad XVII dan Pulau Kalimantan abad XIII. Walaupun Islam masuk di Kerajaan Gowa nanti pada abad XVII dan dijadikan sebagai agama resmi kerajaan. ${ }^{1}$

Masuknya Islam di Kerajaan Gowa sebagai agama resmi kerajaan, menjadi cikal bakal lahir dan berkembangnya Agama Islam di Sulawesi Selatan meskipun ada tiga kerajaan besar yang ada dan saling bekerjasama yaitu, Luwu, Gowa dan Bone. Akan tetapi Kerajaan Gowa yang memegang peranan penting dalam misi dakwah Islamiah, karena Islam sudah menjadi agama resmi kerajaan, maka Raja Gowa dan Tallo sebagai kerajaan kembar memiliki keinginan untuk menyampaikan Agama Islam ke kerajaan-kerajaan yang ada di Sulawesi Selatan khususnya.

Dengan demikian, penyebaran Islam yang ada di SulawesiSelatan kemudian mulai diserukan. Kesepakatan ini tertuang dalam literatur sejarah, dijelaskan bahwa yang menjadi modal utama Kerajaan Gowa menyeruh Islam sampai pada Kerajaan Bone yakni adanya kesepakatan antara Kerajaan Gowa dan Kerajaan Bone di masa lalu yang mengatakan bahwa:

"Barang siapa diantara mereka yang menemukan jalan yang lebih baik, makaia berkewajiban memberitahukan tentang jalan yang baik itu kepada yang lainnya". ${ }^{2}$

\footnotetext{
${ }^{1}$ Isra Husain, "Studi Tentang Penyebaran Dan Perkembangan Agama Islam Di Bantaeng”, "Skripsi” (Ujung Pandang: Fak Adab IAIN Alauddin, 1983), h. 37.

${ }^{2}$ Edward L. Poelinggoman, Sejarah Perkembangan Kerajaan-Kerajaan di Sulawesi Selatan (Makassar: BALIKBAN, 2003),h.129.
} 
Perjanjian ini ada sejak lama, dengan demikian Sultan Alauddin (15931539 M) menyerukan Islam ke Kerajaan Bone. Dijadikannya Islam sebagai agama resmi di Kerajaan Gowa pada abad ke-XVII maka dakwah Islampun mulai dikembangkan sampai pada Kerajaan Bone, yang dibawa oleh Sultan Alauddin. meskipun pada awalnya pihak kerajaan menolak ajakan tersebut namun pada akhirnya Islampun masuk pada masa pemerintahan La Tenriruwa (1611 M) yang pada saat itu menjadi Raja Bone XI dan hanya menjabat kurang lebih tiga bulan lamanya. ${ }^{3}$

Masuknya Islam di Kerajaan Bone, dianggap perlu adanya pengembangan Islam pada kerajaan tersebut. Raja Bone XIII, La Maddaremmeng atau yang nama Islamnya Sultan Muhammad Shaleh yang pada saat itu memimpin kerajaan, melakukan pembaharuan yang lebih fokus pada keislaman sehingga Bone mampu menjadi salah satu Kerajaan Islam yang ada di Sulawesi pada umumnya dan Bone pada khususnya. Selain dari pada itu kerajaan tetangganya pun seperti Sopeng, Wajo, Sidenreng, dan Sawitto mendapat pengaruh dari keinginannya menjadikan Kerajaan Bone sebagai Kerajaan Islami. ${ }^{4}$

Meskipun Kerajaan Bone masa pemerintahan La Maddaremmeng, telah dikaji sebelumnya, namun hal tersebut tidak secara spesifik membahas tentang pengembangan Syiar Islam pada masa La Maddaremmeng, akan tetapi lebih kepada sistem pemerintahan yang dibangun serta peperangan antara Kerajaan Bone dengan Kerajaan Gowa. Selain itu, pendekatan yang digunakan tidak mengunakan pendekatan agama sehingga lebih bersifat umum.

Oleh karena itu, penulis lebih fokus pada syiar Islam yang dilakukan oleh La Maddaremmeng sebagai Raja Bone XIII, beliau terkenal sangat giat dalam membentuk pemerintahan yang berbasis Islam terbukti pada kebijakankebijakan yang dikeluarkannya, sehingga penulis menganggap bahwa hal tersebut 2014), h,58.

${ }^{3}$ H. L. Purnama, Kerajaan Bone Penuh Pergolakan Heroik (Makassar: Arus Timur,

${ }^{4}$ Kaharuddin, "Kerajaan Bone Pada Masa Pemerintahan La Maddaremmeng”, (16251644), Skripsi (Makassar: Fakultas Ilmu Sosial Universitas Negeri Makassar,2010), h.15. 
bagian dari Dakwah Islam yang sangat penting sehingga dijadikan sebagai aturan kerajaan meskipun banyak yang kontra dengan kebijakan tersebut.

\section{B. Usaha La Maddaremmeng (Sultan Muhammad Shaleh)}

\section{Menghilangkan Perbudakan}

Sistem perbudakaan di Kerajaan Bone, memang sudah menjadi budaya ditenga-tenga masyarakat serta sudah menjadi warisan turun-temurung dari nenek moyang di masa lalu.Namun setelah masuk Ajaran Islam, sedikit demi sedikit sistem perbudakan ini mulai terkikis. Adanya perbedaan hak antarsesama manusia pada masapemerintahan La Maddaremmeng, sehinggaLa Maddaremmeng menilai hal tersebut sebagai masalah sosial ditenga-tenga masyarakat Kerajaan Bone.

Sehingga harus diperbaharui agar supaya kehidupan masyarakat lebih sejahtera. Sistem perbudakaan ini, tidak hanya bertentangan dengan norma Agama Islam akan tetapi juga pada tatanan sosial yang tentu sangat berpengaruh terhadap karakter manusianya. Misalnya perlakuan seorang tuan terhadap budaknya, sangat berbeda dengan sesamanya para bangsawan, seorang budak dapat diperlakukan sesuka hati tuannya karena dianggap sebagai budak saja yang sangat rendah derajatnya di mata manusia. Sebagaimana dalam lontarak disebutkan bahwa :

"Iyana (La Maddaremmeng) mapparéntangngi ri to Boné pamaradékai sininna ata riyalaé ri laleng musu' kuwaé topa sininna ata riduiriyé. Iya muwasa' ata mana'é manennungeng wedding mui ripowata naé riyagi lise' bolai padatosa' séajingngé". 5

Artinya:

Inilah (La Maddaremmeng) yang memerintahkan kepada masyarakat Boné untuk memerdekakan seluruh sahaya yang diambil dalam peperangan, juga seluruh sahaya yang dibeli. Adapun sahaya warisan yang telah lama mangabdi dibolehkan dijadikan sahaya, tetapi harus diperlakukan mausiawi sebagaimana perlakuan terhadap keluarga sendiri.

Sistem penghapusan budak, merupakan rintisan La Maddaremmeng yang pada dasarnya menginginkan syariat Islam berlaku dalam ruang lingkup Kerajaan

${ }^{5}$ La Side Daéng Tapala, Lontara'na Petta Malampé'é Gemme'na, Jilid I, (Ujung Pandang: Jajasan Lektur Batuputih, t.th.), h. 28. 
Bone. Aturan baru ini merupakan bagian dari pengembangan Islam pada Kerajaan Bone, sehingga syariat Islam dapat berkembang sertamasyarakat Kerajaan Bone pada umumnyaakanpahamtentangaturan-aturan yang terdapatdalamAjaran Islam.

\section{Membentuk Dewan Syarat (Parewa Sara')}

Perjuangan yang dilakukan oleh La Maddaremmeng dalam melakukan pengembangan Islam di Kerajaan Bone, ternyata tidak hanya pada bidang sosial,saja akan tetapi pada bidang yang lain juga telah dilakukan perombakan pada sistem pemerintahan Kerajaan Bone.Pada masa Pra Islam di Kerajaan Bone memang sudah dikenal konstitusi yang mengatur masyarakat Kerajaan Bone pada umumnya, baik dalam kehidupan sehari-hari maupun pada bidang religi semua itu di rangkum dalam Konsep Pangaderreng yang di dalamnya terdapat empat pilar yakni Adat (Ade'), Undang-Undang(Rapang), Peradilan (Bicara), klasifikasi(Wari').

Empat konsep yang dianut oleh pemerintahan di Kerajaan Bone, merupakan undang-undang yang sudah lama digunakan. Setelah masuknya Islam maka dipandang perlu adanya sistem dalam pemerintahan yang khusus pada bagian keagamaan, maka lahirlah yang disebut dengan Konsep Sara' atau yang dikenal dengan Syariat Islam, memadukan antara hukum tradisional dengan hukum agama merupakan jalan yang harus ditempuh oleh Raja La Maddaremmeng agar supaya pengetahuan tentang Islam lebih mendalam lagi.

Ada beberapa bidang kerja dari pejabat syarait pada masa Raja La Maddaremmeng, diantaranya mengenai peradilan agama, perkawinan, perceraian, talaq/rujuk, harta warisan, hibah, wakaf, urusan haji, zakat, infak, sedekah, penetapan mulai puasa, lebaran, shalat Jumat, serta hari-hari besar Islam lainnya. Dengan demikian dibentuklah beberapa lembaga dewa syara' dan pejabatpejabatnya antara lain Qadhi yang diberi gelar Petta Kali'e, Imam yang bergelar Petta Imang, Khatib yang diberi gelar Puang Katte, dan Bilal yang diberi gelar Bilala. 
Selain itu petugas tambahan juga diperlukan seperti marbot, staf panitia zakat, juru penerangan atau muballiq, guru mengaji dan lain sebagainya. ${ }^{6}$ Para petugas inilah yang diberikan amanah oleh Raja La Maddaremmeng, agar melaksanakan tugas dengan sebaik-baiknya dan sesuai dengan wewenang masingmasing pejabatnya. Selain pembentukan lembaga dan para pejabat, sarana peribadatan juga ditingkatkan untuk memudahkan dalam hal beribadah salah satu diantaranya yakni pembangunan mesjid di Lalebbata (Ibu Kota Kerajaan Bone) mesjid ini diberi nama Al-Mujahidin atau biasa juga disebut Masiji Laungnge yang artinya mesjid tertua di Watampone.

\section{Pemurnian Ajaran Islam}

Proses pemurnian Agama Islam memerlukan waktu yang lama tidak dapat dilakukan secara instan, hal tersebut karena kepercayaan nenek moyang masyarakat Kerajaan Bone masih melekat pada saat Islam sudah masuk di kerajaan tersebut.La Maddaremmeng sebagai seorang raja yang dikenal sangat patuhterhadapaturan Islam sebagaimana yang tercantumdalamLontarak, sebagaiberikut :

Iyatonaé Arung mangkau' ri aseng maséro magama. Na maraja pakkamase ri padanna winru' ri Allah Ta'ala. ${ }^{7}$

Artinya:

Inilah raja yang berkuasa yang diterkenal religius, lagi tinggi kasih sayangnya sesama ciptaan Allah swt.

Masa pemerintahan La Maddaremmeng masyarakatnya masih banyak yang sulit membedakan antara kebudayaan lokal dengan syariat Islam sehingga masih banyak praktek-praktek yang bertentangan dengan Islam. Sebagai seorang raja yang terkenal akan kesholehannya, tentu Ia juga akan memberantas hal yang bertentangandenganAjaran Islamsepertihalnyaperbuatan syirik, tahyul, khurafat, dan bi'dah.

Salah satu contoh pelaksanaan upacara ritual untuk menghormati yang mereka anggap sebagai pencetus dan penolak bencana, maka dengan melaksanakan upacara atau memberikan sesajen kepadanya dapatlah terhindar

${ }^{6}$ Abdul Qahhar, Batarana Tana Bone Matasilompoe Manurunge Ri Matajang (Gowa: Yayasan Al Muallim, 2011), h. 144.

${ }^{7}$ La Side Daéng Tapala, Lontara'na Petta Malampé'é Gemme’na, Jilid I, (Ujung Pandang: Jajasan Lektur Batuputih, t.th.), h. 278. 
dari murkanya, dan sebaliknya mendapat simpati dari yangmereka anggap sebagai penunggu suatu tempat tertentu seperti roh leluhur dan sebagainya. ${ }^{8}$

Selain kegiatan dakwahnya La Maddaremmeng juga memerintahkan kepada seluruh jajaran kerajaan serta pada masyarakat pada umumnya untuk membasmi segala tempat-tempat yang dianggap keramat serta tempat pemujaan lainnya yang dianggap dapat merusak aqidah masyarakat Kerajaan Bone. ${ }^{9}$ Kegiatan pemurnian agama ini, semata-mata untuk memurnikan keyakinan masyarakat Kerajaan Bone yang masih terkontaminasi dengan keyakinan nenek moyang mereka. Dengan begitu masyarakat kerajaan akan lebih paham tentang konsep tauhid dalam Islam.

\section{Tantangan La Maddaremmeng}

\section{Tantangan Internal}

Wé Tenrisoloreng, merupakan ibu kandung La Maddaremmeng yang bergelar Makkalarue dan juga sebagai pemegang tahta Datu Pattiro masuk diantaraorang-orang yang menentang kebijakan La Maddaremmeng. Setelah La Maddaremmeng, mengeluarkan beberapa kebijakan yang sangat menjunjung nilai-nilai kemanusiaan, La Maddaremmeng tidak menyangka bahwa tokoh utama yang menjadi bagian oposisi yakni ibunya sendiri. ${ }^{10}$

Dalam lontarak disebutkan bahwa :

Namaégana kuwa arung nenniya tau décéng riyagelli ri arumponé. Namukka' teng pudu-pudu'na pamaradékai ata ala musu'na iyarégga ata naduiriyé. Naé kaminang magettengngé téya siseng pamaradékai atanna datuésa' ri Pattiro indo' topajajiyanna arumponé. ${ }^{11}$

Artinya:

Banyaklah bangsawan dan masyarakat biasa yang dimurkai oleh Arumponé (La Maddaremmeng) sebab tidak sudi memerdekakan

${ }^{8}$ Izarwisma Mardanas, Arsitekstur Tradisionsal Daerah Sulawesi Selatan, (Ujung Pandang, Proyek Inventarisasi dan Dokumentasi Kebudayaan Daerah, 1985), h. 20-21.

${ }^{9}$ Hasnawati, "Peranan Raja-Raja Bone dalam Pengembangan Islam", "Skripsi” (Ujung Pandang: Fakultas Adab IAIN, 1991), h. 58.

${ }^{10}$ Abdurrazak Daeng Patunru dkk., Sejarah Bone (Ujung Pandang: Yayasan Kebudayaan Sulawesi Selatan, 1989), h. 119.

${ }^{11}$ La Side Daéng Tapala, Lontara'na Petta Malampéé Gemme’na, Jilid I, (Ujung Pandang: Jajasan Lektur Batuputih, t.th), h. 28. 
sahayanya, baik sahaya yang didapat dari perang maupun sahaya yang dibeli. Adapun yang paling keras menolak memerdekakan sahayanya adalah Datu Pattiro, ibu kandung Arumponé (La Maddaremmeng).

Dilihat dari hubungan keluarga sangatlah dekat akan tetapi perbedaan paham serta kecintaan terhadap dunia akan mengubah segalanya, sekali pun itu adalah orang tua La Maddaremmeng sendiri. Secara genetik, yang seharusnya menjadi motivasi utama dalam melaksanakan kebijakan La Maddaremmeng yakni ibunya. Akan tetapikarena ibunya berada pada barisan oposisi, maka La Maddaremmeng dengan keyakinan yang teguh menegakkan syariat Islam harus mampu berhadapan dengan ibunya demi penegakansyariat Islam.

Pihak oposisi menganggap tidak diuntungkan dari kebijakan La Maddaremmeng, karena tidak lagi mendapat pesuruh yang yang dapat dipekerjakan secara suka rela oleh seorang tuan atau bangsawan. Selain itu, pada umumnya masyarakat SulawesiSelatan mengenal sistem sosial bahwasanya siapa yang yang memiliki banyak budak maka orang tersebut sangatlah terpandang dan disegani oleh masyarakat pada umumnya. $^{12}$ Meskipun demikian La Maddaremmeng tetap pada pendiriannya untuk melaksakan aturan baru tersebut pada kerajaannya.

\section{Tantangan Eksternal}

Terbukanya kembali pintu peperangan antara Kerajaan Bone dan Kerajaan Gowa menurut analisa penulis karena adanya problem yang terdapat dalam internal kerajaan Bone yang berdampak pada kerajaan lainnya, apalagi kerajaan tersebut memiliki kepentingan di dalamnya sehingga pihak Kerajaan Gowa kembali mengambil andil di dalamnya. Namun sebelum lebih jauh melangkah pihak Kerajaan Gowa juga sangat jeli melihat kondisi politik pada saat itu dengan menggunakan pendekatan kekeluargaan untuk menuntaskan permasalahan tersebut.

Salah satu jalan yang ditempuh oleh Kerajaan Gowa yang dipimpin oleh Sultan Malikussaid, adalah mengunakan jalan damai hal ini dilakukan untuk

${ }^{12}$ La Side Daéng Tapala, Lontara'na Petta Malampé'é Gemme'na, Jilid I, (Ujung Pandang: Jajasan Lektur Batuputih, t.th.), h. 28-29. 
menjaga pandangan dunia internasional agar tetap baik. Jalan damai ini juga dilakukan untuk mengembalikan hubungan yang baik antara La Maddaremmeng dengan ibunya serta para bangsawan yang ikut pada barisan oposisi. Akan tetapi, dengan catatan bahwa semua kebijakan yang dikeluarkan oleh Raja La Maddaremmeng harus dicabut kembali karena dianggap tidak sesuai dengan tatanan sosial dan budaya yang telah mapan di Kerajaan Bone.

Disebutkan dalam lontarak sebagai berikut :

Aga nassurona karaengnge paka inge'i arungpone. Nassuro suddungngi ritu parentana. ${ }^{13}$

Artinya:

Maka menyuruhlah karaengnge (Sultan Malikussaid) mengingatkan Arumpone (La Maddaremmeng) agar menarik kebijakannya.

Setelah Sultan Malikussaid mengirim surat ke Kerajaan Bone dan diterima oleh La Maddaremmeng, maka La Maddaremmeng dengan tegas menolak seruan tersebut. Menolaknya Raja Bone atas seruan itu, maka jalur konflik pun tidak dapat dibendung dan La Maddaremmeng dengan penuh keyakinan karena telah menjalan kan syariat Islam maka akan siap menerima konsekwensinya sekalipun dalam bentuk peperang antarakerajaan.

Alasan inilah yang kemudian digunakan oleh Kerajaan Gowa untuk kembali menyerang Kerajaan Bone, dengan mengatasnamakan pembelaan terhadap ibu La Maddaremmeng tetapi semua itu tidak lupuk dari kepentingan politik yang pada akhirnya Kerajaan Bone harus menjadi negara bagian Kerajaan Gowa setelah kalah pada saatberperang di Passempe.

\section{Kesimpulan}

La Maddaremmeng mengeluarkan kebijakan diantaranya penghapusan budak, karena raja-raja sebelumnya tidak pernah mengeluarkan kebijakan yang serupa. Ia juga membentuk Lembaga agama yang disebut dewan syara' (ParewaSyara'), serta memurnikan agama Islam yang pada masa La Maddaremmeng masyarakat masih banyak mencampuradukkan antara agama dan

${ }^{13}$ La Side Daéng Tapala, Lontara'na Petta Malampéé Gemme’na, Jilid I, (Ujung Pandang: Jajasan Lektur Batuputih, t.th), h. 29. 
budaya lokal. Semua hal tersebut dilakukan oleh La Maddaremmeng untuk peningkatan kualitas keagamaan di Kerajaan Bone. Namun tidak semua jalan yang ditempuh berjalan dengan mulus, La Maddaremmeng dalam menjalankan kebijakannya banyak mendapat tantangan. Diantaranya dating dari internal kerajaan diantaranya We Tenrisoloreng (Ibu La Maddaremmeng) yang tidak sepakat dengan kebijakan sang anak. Kerajaan Bone tepatnya masa Raja La Maddaremmeng masih banyak peningkatan syiar Islam yang dilakukan olehnya dan hal tersebut belum terekspos secara mendalam terlebih pada pengaruh La Maddaremmeng di Kerajaan Bugis yang berdampingan dengan Kerajaannya yang juga diharapkan dapat menjadikan syariat Islam sebagai asas kerajaannya.

\section{DAFTAR PUSTAKA}

Husain, Isra. "Studi Tentang Penyebaran Dan Perkembangan Agama Islam Di Bantaeng”, Skripsi Ujung Pandang: Fak Adab IAIN Alauddin, 1983.

Hasnawati, "Peranan Raja-Raja Bone dalam Pengembangan Islam", Skripsi Ujung Pandang: Fakultas Adab IAIN, 1991.

Kaharuddin, "Kerajaan Bone Pada Masa Pemerintahan La Maddaremmeng”, 1625-1644, Skripsi Makassar: Fakultas Ilmu Sosial Universitas Negeri Makassar,2010.

Mardanas, Izarwisma. Arsitekstur Tradisionsal Daerah Sulawesi Selatan, Ujung Pandang, Proyek Inventarisasi dan Dokumentasi Kebudayaan Daerah, 1985 .

Poelinggoman,Edward L. Sejarah Perkembangan Kerajaan-Kerajaan di Sulawesi Selatan Makassar: BALIKBAN, 2003. Timur, 2014.

Purnama, H. L. Kerajaan Bone Penuh Pergolakan Heroik Makassar: Arus

Patunru, Abdurrazak Daeng dkk. Sejarah Bone. Ujung Pandang: Yayasan Kebudayaan Sulawesi Selatan, 1989.

Qahhar, Abdul. Batarana Tana Bone Matasilompoe Manurunge Ri Matajang Gowa: Yayasan Al Muallim, 2011.

Tapala,La Side Daéng.Lontara'na Petta Malampé'é Gemme’na, Jilid I, Ujung Pandang: Jajasan Lektur Batuputih, t.th. 